\title{
Dissociated neurons of the pupal honeybee brain in cell culture
}

\author{
S. KREISSL and G. BICKER \\ Institut für Neurobiologie der FU Berlin, Königin-Luise-Str. 28/30, D-1000 Berlin 33, FRG
}

\begin{abstract}
Summary
Primary cell cultures were prepared from specific regions of the pupal honeybee brain which are involved in proboscis extension learning. Defined areas could be dissociated purely by mechanical treatment. We show that cultured neurons regenerate new neurites and remain viable for up to three weeks in a serum-free, chemically-defined medium. Several labelling techniques were employed to identify subpopulations of cultured neurons. For example, acetylcholinesterase staining; fluorescent beads to distinguish identified cell populations of co-cultured brain areas; various markers for surface antigens such as a monoclonal antibody to olfactory projection neurons of the antennoglomerular tracts and monopolar cells of the optic lobes, as well as anti-HRP immunoreactivity and $\alpha$-bungarotoxin binding; and various antisera for detecting transmitter phenotype. The appearance of transmitter-immunoreactive cells agreed closely with that expected from their known distribution in situ. Our results suggest that cultured cells retain surface properties and transmitter phenotype of their in vivo counterparts, despite differences in basic morphology. Thus our culture system provides the important initial step for future in vitro investigations of the cellular and electrophysiological properties of neurons mediating proboscis extension learning.
\end{abstract}

\section{Introduction}

Primary cell cultures provide a useful tool for studying the shape, function and chemistry of neurons in a simplified and controlled environment. Since the introduction of cell culture techniques to study axonal outgrowth of embryonic cockroach neurons (Chen \& Levi-Montalcini, 1970) the investigations of primary cultured insect nerve cells have so far been mainly directed towards an understanding of their growth, electrophysiological membrane, pharmacological, and ligand binding properties (Beadle \& Hicks, 1985; Giles \& Usherwood, 1985; Beadle et al., 1987; Lees \& Beadle, 1988; Wu, 1988; Hayashi \& Hildebrand, 1990; Stengl \& Hildebrand, 1990).

The CNS of the honeybee has provided a rich source of behavioural research topics (Frisch 1967; Menzel \& Mercer, 1987). Basic forms of learning such as habituation (Braun \& Bicker, 1992), sensitization (Mauelshagen et al., 1989) and classical conditioning (Menzel et al., 1974) have been investigated in restrained animals. Systemic pharmacology influencing aminergic transmission permits the dissociation of memory storage from retrieval processes (Mercer \& Menzel, 1982; Bicker \& Menzel, 1989) or the demonstration of aminergic mechanisms in the state dependency of habituation (Braun \& Bicker, 1992). Based on

the well-described functional neuroanatomy (Mobbs, 1985), the chemical neuroanatomy of the bee brain (Bicker et al., 1987) is developing rapidly. Autoradiographic and immunocytochemical methods have been used to map receptor distributions (Kreissl \& Bicker, 1989; Scheidler et al., 1990) and identified aminergic neurons have been detected by immunocy tochemistry and stained intracellularly (Rehder et al., 1987).

The chief neuropiles mediating proboscis extension in response to antennal sugar water stimulation and also associative learning of this reflex are the antennal lobe, the mushroom bodies, parts of the protocerebrum, and the suboesophageal ganglion (Mobbs, 1985; Bicker \& Menzel, 1989). Chemosensory afferents terminate in the glomeruli of the antennal lobe. Relay neurons transmit olfactory information through antennoglomerular tracts into the mushroom body and lateral protocerebrum. The suboesophageal ganglion contains the motor circuits and motoneurons responsible for the extension of the proboscis.

Recently it has proven possible to establish dissociated cultures from pupal antennal lobes of the honeybee, demonstrating morphological and ultrastructural differences between neurons and glial cells (Gascuel et al., 1991). We have prepared primary cell 
cultures from all parts of the brain of the honeybee and describe here transmitter-related properties of neurons. We present evidence that living antennal projection neurons can be distinguished in vitro from antennal local interneurons by means of a monoclonal antibody.

\section{Materials and methods}

\section{Preparation of primary cell cultures}

Three days before adult eclosion, brains of honeybee pupae were dissected out of the head capsule in cold culture medium. In order to match the proline content and osmolarity of the honeybee medium developed by Kaatz and colleagues (1985). L-15 medium (Gibco) was supplemented with $4 \mathrm{~g}$ glucose, $2.5 \mathrm{~g}$ fructose, $24 \mathrm{~g}$ sucrose, and $3.3 \mathrm{~g}$

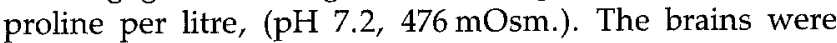
incubated in hypertonic culture medium (culture medium supplemented with additional $20 \mathrm{gl}^{-1}$ sucrose, $585 \mathrm{mOsm}$.) for 5-10 min, and ganglion sheaths were subsequently removed. The retina was removed from the optic lobes and the ocelli from the dorsal protocerebrum since these neuropiles and the ganglion sheaths appeared to inhibit neurite growth. Mushroom bodies, antennal lobes, optic lobes, suboesophageal ganglion, and the remaining cerebral tissue were dissected and pooled seperately in cold, $\mathrm{Ca}^{2+}$ and $\mathrm{Mg}^{2+}$ free honeybee ringer. Normal honeybee ringer was composed of: $\mathrm{NaCl} 135 \mathrm{mM}, \mathrm{KCl} 5 \mathrm{~mm}, \mathrm{MgCl}_{2} 10 \mathrm{mM}, \mathrm{CaCl}_{2}$ $1.6 \mathrm{mM}$, and tris-HCl-buffer $65 \mathrm{~mm}$ ( $\mathrm{pH} 7.2$ ). In divalent cation free ringer, osmolarity was adjusted by the addition of tris- $\mathrm{HCl}$. After several rinses with culture medium, brain fragments of several brains were dissociated by gentle trituration with a $100 \mu \mathrm{l}$ plastic pipette tip in an eppendorf tube under sterile conditions. Tissue debris were allowed to settle down for three minutes and the cell containing supernatant was placed in a sterile tube. The cell density was adjusted to about $5 \times 10^{5}$ cells per $\mathrm{ml}$, and a volume of $100 \mu \mathrm{l}$ of the final cell suspension was placed in the centre of uncoated plastic culture dishes (Falcon 3001, $35 \mathrm{~mm}$ ). Cells were allowed to adhere to the bottom of the culture dish for 3-5 min. Dishes were subsequently filled with $2 \mathrm{ml}$ of culture medium, followed by repeated washes. Cultures were kept in a $29^{\circ} \mathrm{C}$ humidified culture chamber. Photomicrographs of living neurons were taken with a Zeiss Axiovert microscope using phase contrast optics.

\section{Viability}

Viability of the cell cultures was assayed by fluorescein diacetate in combination with ethidium bromide counterstaining. Viewed through a FITC filter combination, nuclei of dead cells showed orange ethidium bromide fluorescence while the cytoplasm of living cells displayed the fluorescein. staining.

Cultures were incubated with culture medium containing $400 \mu \mathrm{g} \mathrm{ml}^{-1}$ ethidium bromide and $410 \mu \mathrm{g} \mathrm{ml}^{-1}$ fluorescein diacetate for $5 \mathrm{~min}$, and subsequently washed extensively with culture medium. Viability was determined immediately after incubation using the FITC filter combination of the Zeiss Axiovert microscope.

\section{Phalloidin staining}

In order to visualize actin filaments in cultured neurons, the culture medium was replaced by a solution containing $50 \mu \mathrm{l}$ rhodamine-phalloidin (Molecular Probes), and $50 \mu \mathrm{g}$ lysophosphatidylcholine in $1 \mathrm{ml} 4 \%$ paraformaldehyde diluted in PBS. Culture dishes were simultaneously fixed and stained for $20 \mathrm{~min}$ at $4^{\circ} \mathrm{C}$. After several rapid washes photomicrographs were taken under a Zeiss Axiovert fluorescence microscope using the rhodamine filter combination.

\section{Anti-HRP staining}

Antibodies against horseradish peroxidase (anti-HRP) label neuron-specific molecules over the entire neuronal surface in fruit flies, grasshoppers (Jan \& Jan, 1982) and bees. In Drosophila embryos anti-HRP antibodies recognize a neuralspecific carbohydrate moiety expressed by at least 17 membrane glycoproteins (Jan \& Jan, 1982; Snow et al., 1987). For neuronal staining with the anti-HRP-antiserum (Sigma) the culture medium was replaced by honeybee Ringer solution and subsequently by $4 \%$ paraformaldehyde. Cultures were fixed for $15 \mathrm{~min}$ at room temperature on a shaker, washed in PBS ( $\mathrm{pH} \mathrm{7.4)} \mathrm{three} \mathrm{times} \mathrm{for} 10 \mathrm{~min}$, and incubated in $1 \%$ $\mathrm{H}_{2} \mathrm{O}_{2}$ for $30 \mathrm{~min}$ in order to inactivate endogenous peroxidase activity. After several washes the anti-HRP serum was applied to the cultured cells at a dilution of $1: 100$ in PBS containing $1 \%$ normal goat serum, $0.1 \%$. Triton $\mathrm{X}-100$ either at $4^{\circ} \mathrm{C}$ overnight or for $60 \mathrm{~min}$ at $37^{\circ} \mathrm{C}$. Immunoreactivity was visualized by the indirect peroxidase method with a secondary HRP-coupled goat-anti-rabbit IgG (Nordic Immunology) diluted 1:200. Either DAB or chloronaphthol served as chromogen for the peroxidase reaction.

\section{Binding of $\alpha$-bungarotoxin}

Nicotinic ACh receptors (AChR) of the insect CNS bind selectively $\alpha$-bungarotoxin ( $\alpha$-Bgt) (Marshall et al., 1990). FITC-coupled $\alpha$-Bgt (Sigma), $10^{-6} \mathrm{M}$ diluted in culture medium, was applied to neurons which were grown in culture for five days. After several brief rinses with culture medium living cultures were rapidly viewed and photographed using the appropriate filter combination.

\section{AChE staining}

Acetylcholinesterase staining was performed according to the procedure described by Karnovsky and Roots (1964) by directly applying the staining solution to fixed cultures.

\section{Glutamate and taurine immunocytochemistry}

Seven days after plating cultures were fixed for $10 \mathrm{~min}$ in $3 \%$ glutaraldehyde dissolved in sodium phosphate buffer $(0.1 \mathrm{M},(\mathrm{pH} 7.4))$. They were rinsed three times for $15 \mathrm{~min}$ with tris-buffered saline (TBS: $0.9 \% \mathrm{NaCl}, 0.1 \mathrm{M}$ tris- $\mathrm{HCl}$ ) and endogenous peroxidase activity was blocked by incubation in $1 \% \mathrm{H}_{2} \mathrm{O}_{2}$ for $30 \mathrm{~min}$ at room temperature. Cultures were again washed with TBS and subsequently incubated with the primary antiserum at $4^{\circ} \mathrm{C}$ overnight. The glutamate antiserum (Immunotech) was applied at a dilution of 1:1000 in TBS, containing $1 \%$ normal goat serum (NGS) and $0.1 \%$ Triton X-100. The taurine antiserum (Immunotech) was diluted 1:500 in the same dilution buffer. For visualization of immunoreactivity the procedure described for anti-HRP staining was employed. 

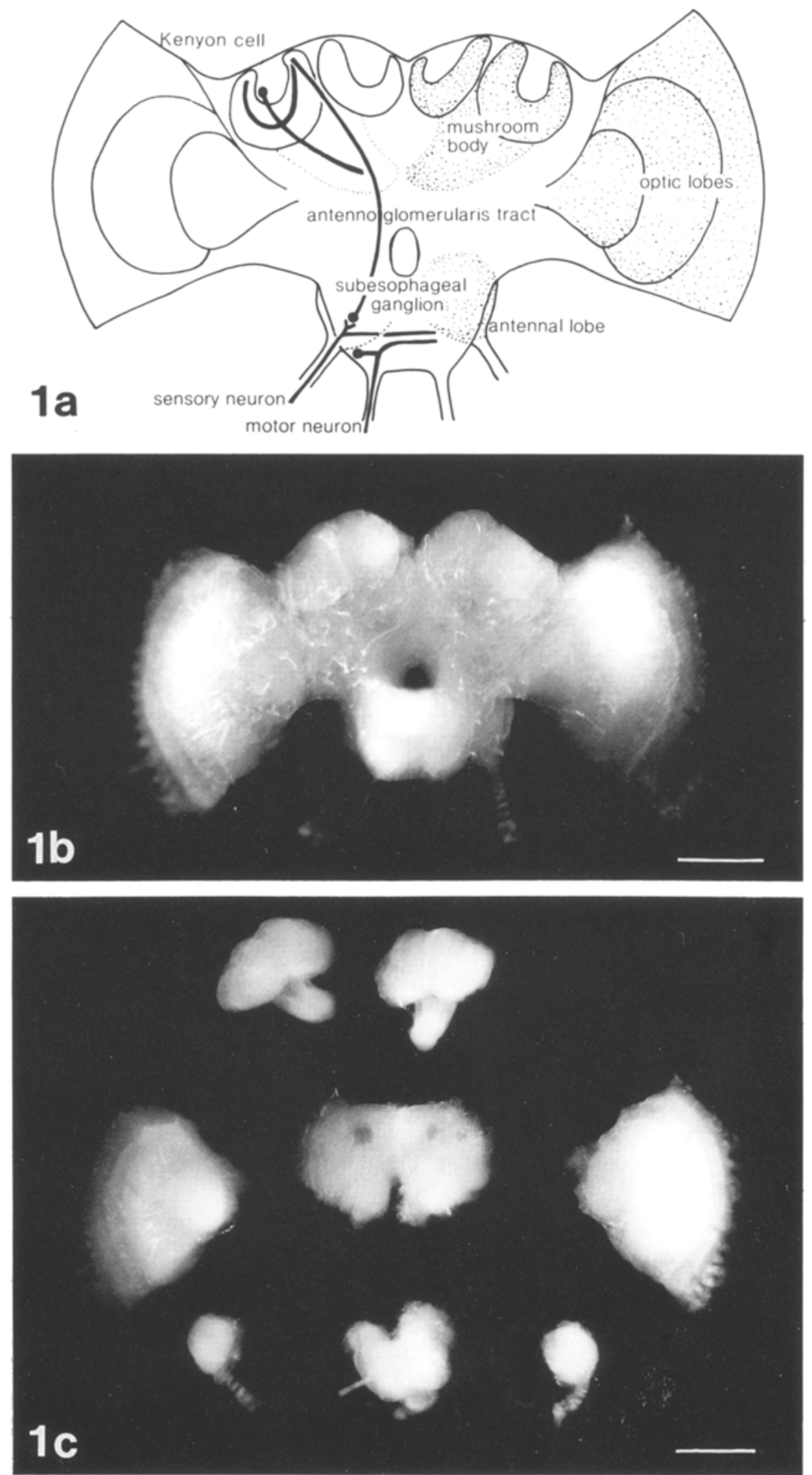

Fig. 1. Dissection of the pupal brain. (a) Schematic drawing of the neuropiles and pathways mediating the proboscis extension reflex. (b) The dissected brain of a honeybee pupa four days after pupal eclosion in a posterior view. Retina and ocelli had already been removed. (c) The pupal brain after cleavage into several neuropilar parts. The natural orientation of the neuropiles is preserved. Top row: mushroom bodies. Middle row: optic lobes and anterior aspect of the protocerebrum. Bottom row: antennal lobes and suboesophageal ganglion in the middle. Scale bars: $300 \mu \mathrm{m}$. 


\section{GABA immunocytochemistry}

After replacement of the growth medium by honeybee Ringer, cells were fixed for $20 \mathrm{~min}$ in $6 \%$ glutaraldehyde dissolved in $0.1 \mathrm{M}$ cacodylate buffer including $1 \%$ sodium metabisulfite (SMB). After several rinses in $0.8 \mathrm{M}$ tris- $\mathrm{HCl}$ containing $1 \% \mathrm{SMB}$ the GABA antiserum (Immunotech) was applied at a dilution of $1: 1000$ in $0.5 \mathrm{M}$ tris- $\mathrm{HCl}(0.1 \%$ $\mathrm{SMB}$, Triton X-100 (pH 7.2)) at $4^{\circ}$ C overnight. Immunoreactivity was detected using a rhodamine conjugated antirabbit antiserum diluted 1:20 (Dakopatts).

\section{Immunocytochemistry with monoclonal antibody FB 45}

We applied a monoclonal antibody secreted by the mouse hybridoma cell line FB 45 (MAB FB 45 (Hofbauer, 1987)) which was immunized with Drosophila brain homogenate to sections and cultures of the honeybee brain. In Drosophila MAB FE 45 stains a population of cells (Hofbauer, 1987) which is thought to be involved in chemosensory information processing. Either frozen sections or paraffin sections of honeybee brains were incubated with the supernatant of the hybridoma cells FB 45 diluted 1:100 in PBS overnight. Binding of the antibody was detected by the indirect peroxidase method using a HRP-labelled secondary goat anti-mouse antiserum (Nordic Immunological) diluted $1: 100$ in PBS. For immunocytochemical identification of cultured neurons either cultures of dissociated antennal lobe cells or of optic lobe cells were incubated with hybridoma supernatant $1: 1$ in culture medium for $6 \mathrm{~h}$ at room temperature. After six washes antibody binding was detected with a FITC coupled goat-anti-mouse antibody at a dilution of $1: 20$ (Dianova). Paraffin sections and cultures were photographed under a Zeiss Axiovert fluorescence microscope.

\section{Latex beads}

Fluorescent latex beads were employed to label growing cells of different brain regions in co-cultures. Cells of the antennal lobe were cultured for three days and incubated with rhodamine coupled latex beads (Polysciences $60 \mathrm{~nm}$ ). We applied a final dilution of 1:20 000 of the suspension supplied by Polysciences. Within a timespan of minutes all antennal lobe neurons incorporated the latex beads. Subsequently the beads were removed by several rinses in normal medium. Unlabelled Kenyon cells were then plated and co-cultured with the antennal lobe neurons.

\section{Results}

The dissection of the honeybee brain is shown in Fig. 1, which also provides a schematic drawing of the neuropiles mediating the proboscis extension reflex (Fig. 1a). The pupal brain was taken out of the head capsule and photographed under a dissecting microscope after the removal of retina and ocelli (Fig. 1b). Figure 1c shows the disjoined parts of the brain and the suboesophageal ganglion.

After mechanical dissociation and plating into culture dishes the somata of the neurons attached to the floor of the uncoated petri dish. Initial diameters of the spherical somata ranged from 5-30 $\mu \mathrm{m}$.
About $50 \%$ of the plated neurons were viable in cell cultures prepared from the various brain parts, as determined one day after plating. Averaged over all neuropiles, viability declined over the course of three weeks to about $10 \%$. Application of the fluorescein diacetate/ethidium bromide staining, however, demonstrated remarkable differences in the viability of cells derived from the various brain areas. For example the protocerebral Kenyon cells, which are the intrinsic constituents of the mushroom bodies, show a decline of viability from initially $62 \%$ to $31 \%$ during 12 days in culture, while the viability of protocerebral cells decline from $48 \%$ to $7 \%$ within the same time span (Fig. 2). During the main part of the investigation viability was simply judged according to morphological criteria, since dying cells showed an increasing number of vacuoles in their somata and fragmented processes while the somata of living cells were phasebright.

\section{Morphology and extension of neurites}

Within one day after plating cells started to sprout new processes (Fig. 3a). A time lapse analysis of neurite extension over six days is shown in Fig. 3. Growth of new neurites occurred both from the occasionally remaining stump of the primary neurite and also from the soma. Unlike the unipolar neurons in the intact nervous tissue many cells in vitro attain a multipolar, highly branched morphology, like the protocerebral neuron shown in Fig. 3.

As shown in Fig. 3 many neuritic branches grew simultaneously, but other growth patterns were also observed. In some cases growth cones with lamellipodia and filopodia were conspicuous at the tips of new neurites (Fig. 4a) while in other cases the ends of extending neurites neurites were not enlarged as observed with phase contrast microscopy (Fig. 4b). When we applied rhodamine-coupled phalloidin to growing neurons the staining was mainly confined to

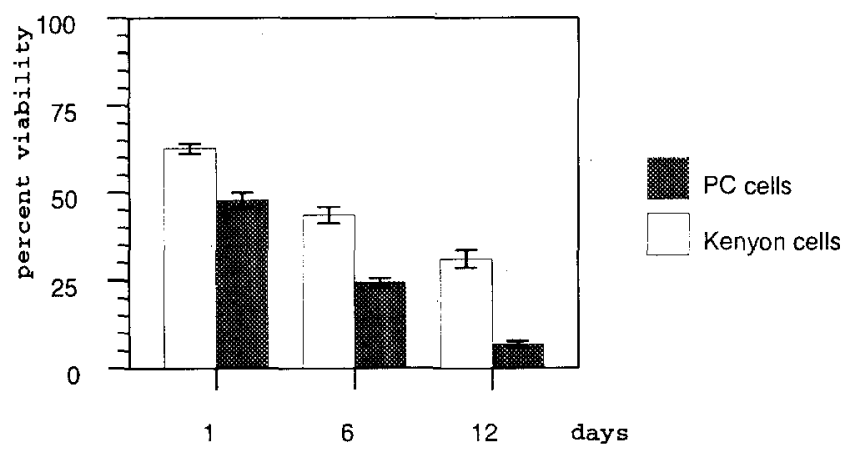

Fig. 2. Viability of protocerebral and Kenyon cells. Viability, as determined by the percentage of fluorescein diacetate positive cells, is plotted against time in culture. Error bars represent SEM. 

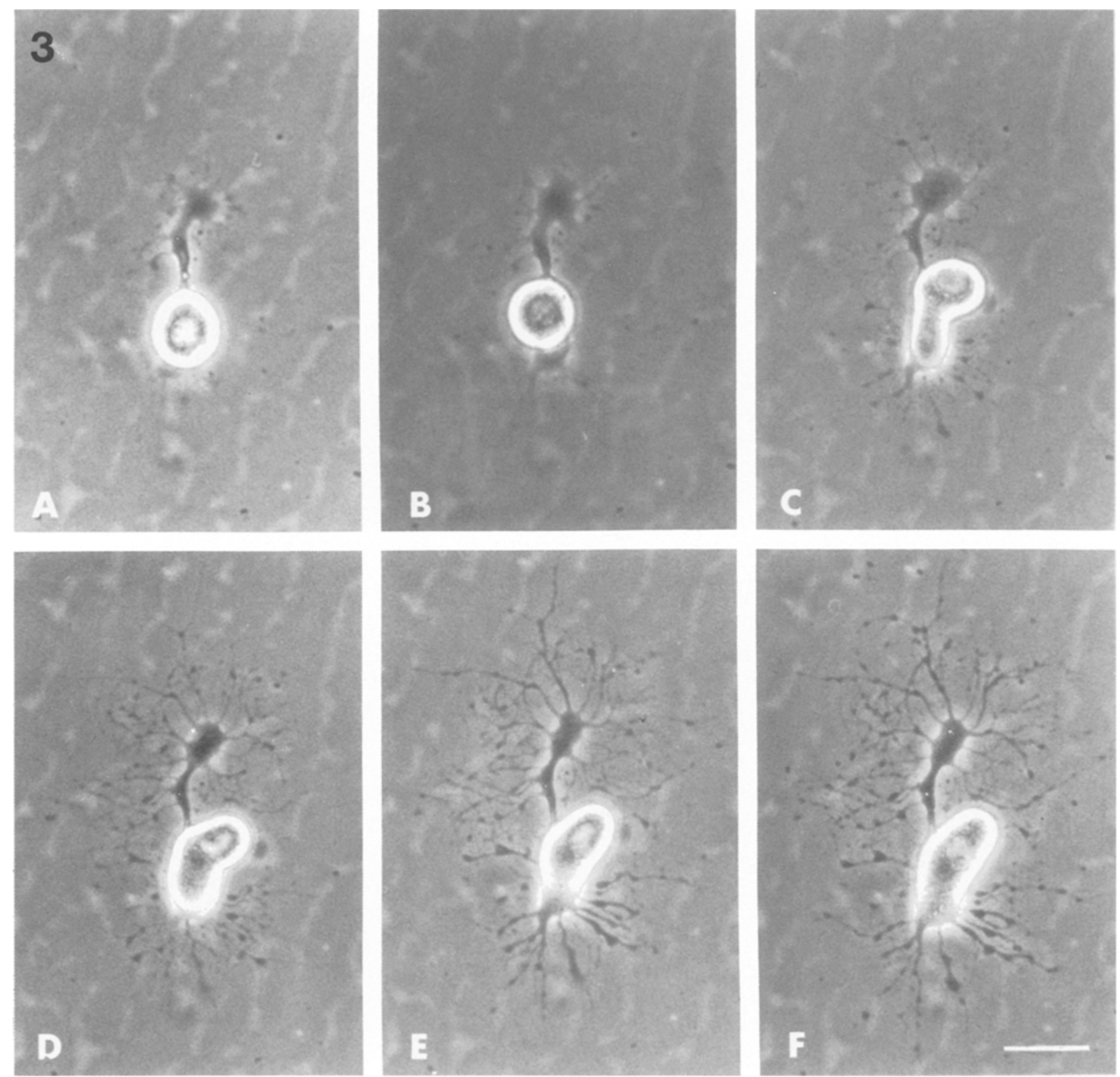

Fig. 3. Neurite growth of a protocerebral neuron. Timelapse record of a neuron in culture, showing the growth of neurites. Frames were taken $24 \mathrm{~h}$ apart beginning at $6 \mathrm{~h}$ after plating. Scale bar: $30 \mu \mathrm{m}$.

the most distal parts of neurites (Fig. 4c, d) demonstrating actin filaments in the extending regions, and sometimes staining was also found in veils surrounding flat cell bodies with a darker appearance. Over time in culture the morphology of the somata changed, either gradually flattening but more often curving up into a pear shaped appearance (Fig. 5a,b).

\section{HRP immunoreactivity}

We employed the anti-HRP antibody to the cell cultures for two main reasons. First, we wondered whether cells of the dissociated nervous tissue retained this neuronal surface marker in vitro. Second, for reasons of methodology to enable visualization of very thin neuritic extensions, which is limited using phase contrast. Almost all cultured cells expressed strong HRP-IR on their entire surface including soma as well as processes. Two HRP-IR antennal lobe neurons with spherical cell bodies and varicose neurites contacting each other are shown in Fig. $5 a, b$. Anti-HRP immunostaining reveals processes of mushroom body intrinsic Kenyon cells which are hardly visible with phase contrast microscopy (Fig. 5c). However, cells with a very low level of HRP-IR were also found (Fig. 5d), which did not express neuron-typical morphology and were presumably of glial origin. Generally the soma of such a cell was surrounded by a lamellipodium-like membrane extension with straightly projecting filaments (Fig. 5d). The cell bodies contained light refracting 

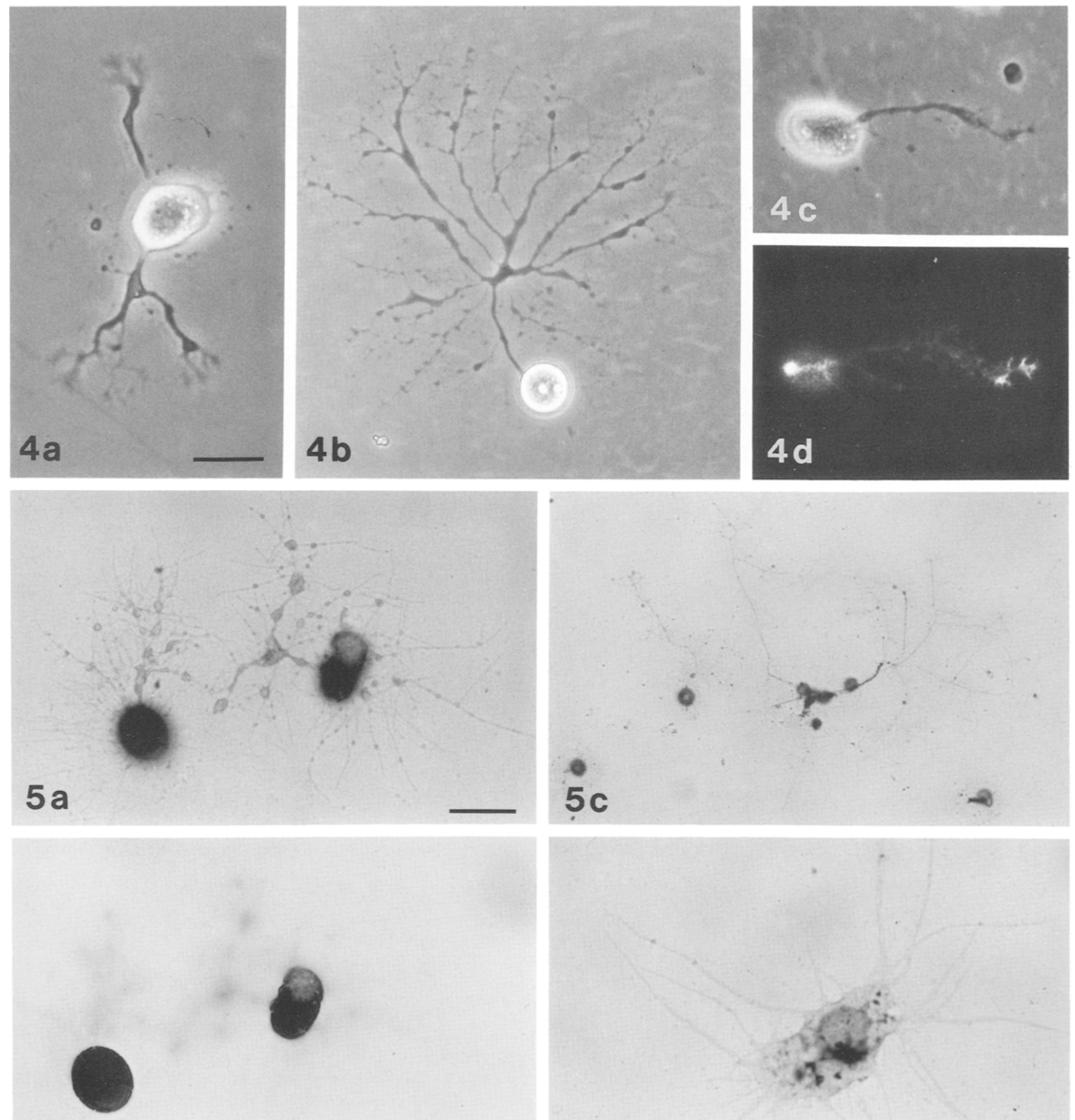

5 b

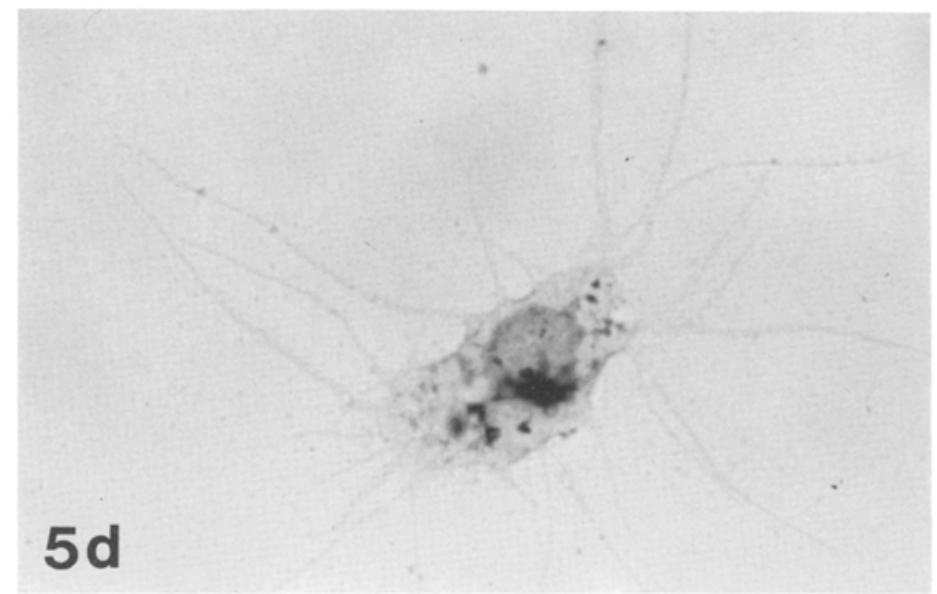

Fig. 4. Extension of neurites. (a) Protocerebral neuron showing growth cones with lamellipodia and filopodia at tips of neurites. (b) Protocerebral neuron without clearly visible growth cones. (c) Phase contrast picture of neuron which was fixed and prepared for phalloidin staining. (d) Neuron of (c) under fluorescence optics. Rhodamine-phalloidin staining in distal parts of growing neurites. Scale bars: $30 \mu \mathrm{m}$.

Fig. 5. Anti-HRP staining. (a,b) Neurites (a) and somata (b) of antennal lobe neurons were photographed in two different focal planes showing HRP-IR on all parts of the cell membrane. Note the contacting processes of the two neurons. (c) Anti-HRP immunostaining reveals neurites of mushroom body intrinsic Kenyon cells grown in culture. (d) Glial cells contain granular inclusions and show weak anti-HRP immunoreactivity compared to staining intensity of neurons. Scale bars: $30 \mu \mathrm{m}$. 

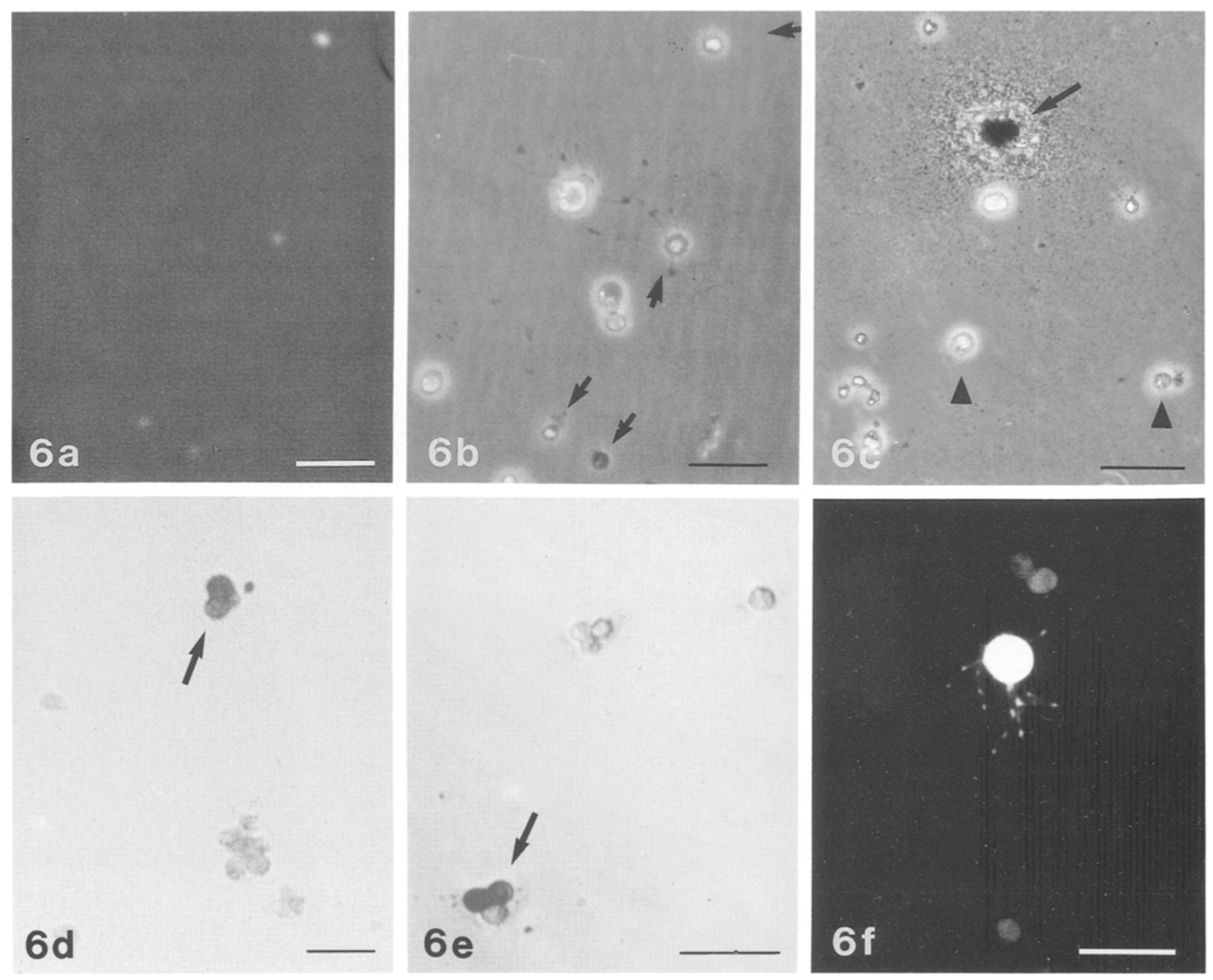

Fig. 6. Transmitter related properties. (a) FITC-coupled $\alpha$-Bgt staining ( $1 \mu \mathrm{M}$ diluted in culture medium of neurons of the optic lobes. (b) Neurons (a) under phase optics. $\alpha$-Bgt-labelled neurons are shown with arrows. (c) AChE positive neuron (arrow) with surrounding dark AChE-active material and a halo of displaced AChE activity surrounding unstained neurons (arrowhead). (d) Glutamate immunoreactivity (arrow) in protocerebral neurons. (e) Taurine immunoreactivity (arrow) in Kenyon cells. (f) GABA immunoreactivity in a neuron of the optic lobes. Immunofluorescence is visible in soma, processes and also in the varicosities. Scale bars: $30 \mu \mathrm{m}$.

granules and inclusions. Unlike the spherical somata of the neurons, the cell bodies of glial cell types were flatter immediately after dissociation, phase-dark, and resembled mammalian fibroblasts in appearance. Glial cells were not as viable as neurons in our culture system and often died within a week.

\section{Transmitter phenotypes}

The neurochemical diversity of neurons provided convenient markers for cell identification within the cultured brain regions. Acetylcholine esterase activity and $\alpha-\mathrm{Bgt}$ binding sites are useful pre- and postsynap- tic markers of cholinergic pathways. We identified binding of FITC coupled $\alpha$-Bgt applied in micromolar concentration to some neurons of the optic lobes while other cultured cells remained unlabelled (Fig. 6a,b). Due to fluorescence bleaching we were not able to photographically document binding in the $100 \mathrm{nM}$ range, which could be observed with dark adapted eyes. Cholinergic neurons are thought to express $\mathrm{AChE}$, which hydrolyzes acetylcholine. A staining method for AChE was applied to the cell cultures from optic lobes showing AChE activity confined within single cells, which were surrounded by a halo of 

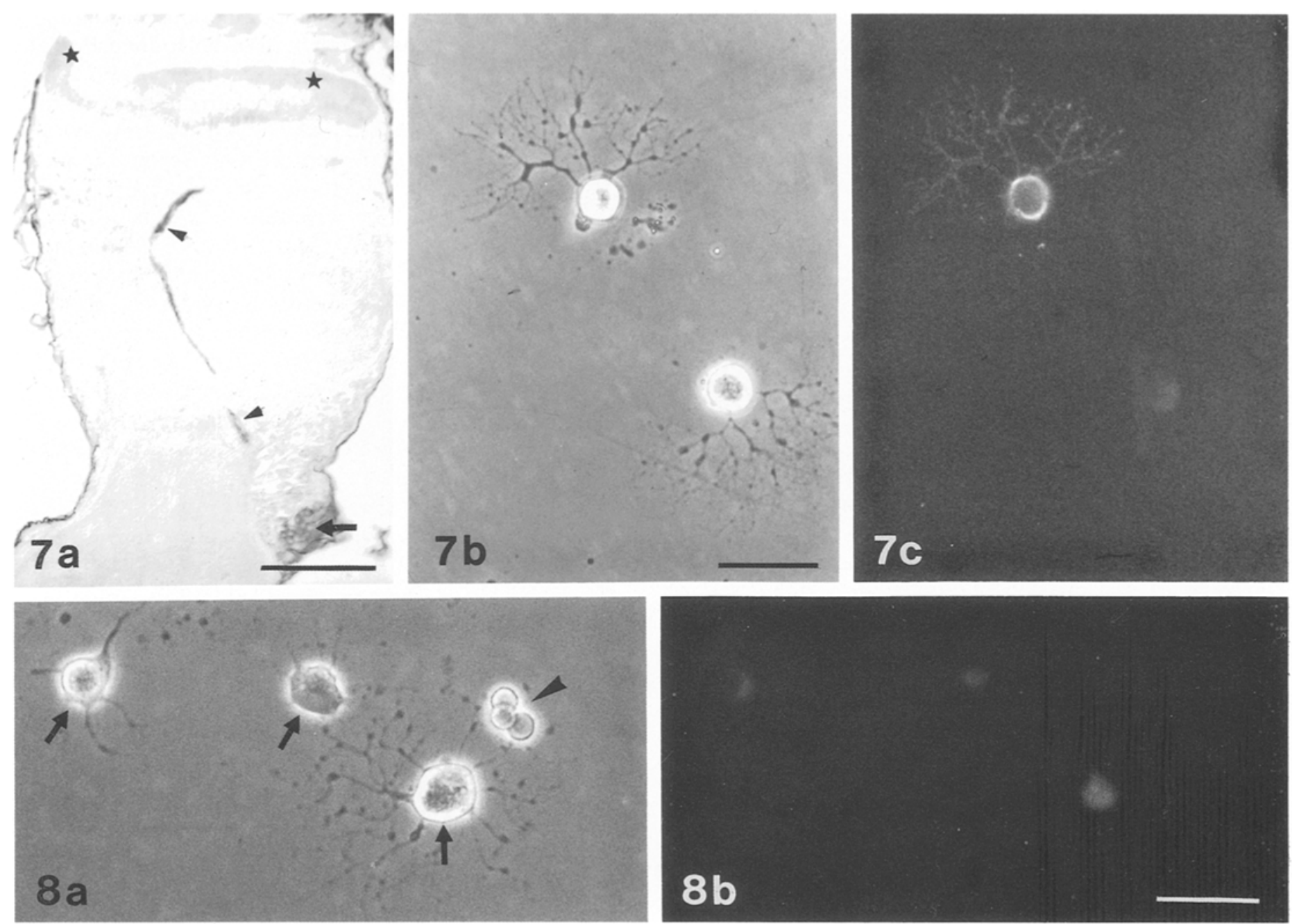

Fig. 7. Identification of living antennoglomerular tract neurons. (a) Monoclonal antibody FB 45 stains the somata (arrow) of the antennal relay neurons, their projections via the median antennoglomerular tract (arrowheads), and their terminals in the lip region of the mushroom body calyces (asterisks) on a sagittal section of the honeybee brain. Immunocytochemistry was performed with the indirect peroxidase method. Scale bar: $100 \mu \mathrm{m}$. (b) Two antennal lobe neurons observed with phase optics. (c) Same neurons as in (b) observed with FITC-fluorescence optics. Indirect immunofluorescence with MAB FB 45 and secondary FITC-coupled antibody labels the surface of a living antennal lobe neuron in vitro. Scale bars: $(\mathrm{b}, \mathrm{c}) 30 \mu \mathrm{m}$.

Fig. 8. Incorporation of fluorescent latex beads. (a) Co-culture of large diameter antennal lobe neurons (arrows) which were incubated with fluorescent latex beads with small diameter Kenyon cells (arrowhead). (b) Living neurons of (a) under fluorescence optics. Antennal lobe neurons display rhodamine fluorescence, due to latex bead uptake, while Kenyon cells remain unlabelled. Scale bar: $30 \mu \mathrm{m}$.

AChE-active material. Neurons in the vicinity, which do not express AChE activity, displace the extracellular halo of AChE activity (Fig. 6c). Since AChE is known to occur in various intracellular and extracellular forms, the AChE-positive neurons presumably secreted a releasable form into the extracellular matrix. In agreement with the absence of AChE activity in Kenyon cells (Kreissl \& Bicker, 1989), no staining was found in cultures of the mushroom bodies.

We detected glutamate immunoreactivity in cultures of the suboesophageal ganglion and in cultures of the protocerebrum and the optic lobes. An example of stained neurons from the protocerebrum is shown in Fig. 6d. Immunoreactivity to glutamate in the bee nervous system has previously been detected in motoneurons and in discrete populations of interneurons (Bicker et al., 1988).

Two main classes of mushroom body-intrinsic Kenyon cells could be distinguished in our culture system according to their soma size. Taurine immunoreactivity appeared to be more intense in cells of a larger diameter (Fig. 6e), which most likely belong to the more peripheral group of Kenyon cells within the cup and around the lip of the calyces (Mobbs, 1982).

GABA immunoreactivity in the cell body and varicose processes (Fig. 6f) was detected in cultured neu- 
rons from all brain areas except mushroom bodies. A quantitative evaluation based on several independent experiments performed in cultures which were maintained for 1 week indicated that ca $7 \%(n=1278)$ of the dissociated neurons were GABA-IR. GABA immunoreactivity is a marker predominantly for local interneurons in all neuropiles of the bee's brain (Schäfer \& Bicker, 1986). The percentage of GABA-IR cells in vitro agrees closely with the reported frequency of $5 \%$ in vivo.

\section{Identification of living cells}

Monoclonal antibodies recognizing surface antigens are useful labels for specific cell types in vitro. MAB FB 45 stained the entire surface of monopolar neurons in the optic lobes and neurons projecting through the median and lateral antennoglomerular tracts. The staining of the median antennoglomerular tract with MAB FB 45 is shown in a sagittal section in Fig. 7a. In cell cultures obtained from the optic lobes less than $4 \%$ of the neurons were stained; these are most likely monopolar cells.

Since MAB FB 45 binds without prior fixation of nervous tissue, living relay neurons of the antennoglomerular tracts could be identified by indirect immunofluorescence in dissociated cultures of the antennal lobes. A living fluorescence labelled neuron and an unstained neuron of the dissociated antennal lobes are shown, together with the corresponding phase optic micrographs, in Fig. $7 \mathrm{~b}, \mathrm{c}$.

In order to distinguish between dissociated cells from different regions of the brain in co-culture, we labelled cells of specific origin by the cellular uptake of fluorescent latex beads in vitro. An application of this method, which may be useful in reconstituting antennoglomurular pathways in vitro, is shown in Fig. 8. Kenyon cells were plated to antennal lobe neurons (Fig. 8a) which had already taken up fluorescent latex beads added to the culture medium. Because the antennal lobe neurons retained the beads for several days they could be distinguished from Kenyon cells based on their fluorescence (Fig. 8b).

\section{Discussion}

\section{Culture system}

In vitro studies on the properties of neurons mediating the proboscis extension reflex are potentially a useful tool for an understanding of the cellular changes accompanying behavioural plasticity in honeybees. Recently Gascuel and colleagues (1991) established cell cultures of neurons and glial cells of the honeybee antennal lobe by using a combination of various commercially available standard media conditioned with honeybee brain explants. We have prepared primary cell cultures from all parts of the brain, with an emphasis on neuronal subpopulations mediating the proboscis extension reflex in order to investigate their cellular and neurochemical properties in isolation from the neuropile and to obtain direct access to the neurons for electrophysiological analysis. Our paper reports survival and differentiation of dissociated honeybee neurons in vitro in a chemicallydefined culture medium. Clearly, our culture system, which is based on a medium with no conditioning factors, supports survival and differentiation of neurons for only up to three weeks. Nevertheless, this is sufficient to test the potential actions of hormones or other factors on neuronal viability and neuritic outgrowth in a defined environment. In addition, we are presently examining the electrophysiological responses of antennoglomerular relay neurons towards application of aminergic transmitters which are powerful modulators of the proboscis extension reflex (Mercer \& Menzel, 1982; Bicker \& Menzel, 1989). Preliminary experiments indicate that the dissociated cells display resting membrane potentials in a range of -35 to $-70 \mathrm{mV}$, rectifying membrane properties, and some of them showed action potentials (Kreissl \& Bicker, 1990).

\section{Morphology and cellular phenotype}

After plating, outgrowth of new neurites occurred either directly from the soma or from the occasionally remaining stumps of the primary neurite, in most cases resulting in a multipolar morphology of the cultured neurons. In several instances we observed that extension of neurites occurred by means of clearly visible growth cones.

During normal development of nervous systems individual neurons are exposed to an array of specific external cues, which sculpt their final shape, and which are not present in dissociated cell cultures. Therefore the sprouting of multiple neurites from the somata in our culture system is in contrast to the unipolar shape of insect neurons in situ (Strausfeld, 1976).

In cultures of antennal lobe neurons of the honeybee a rather complementary cytoskeletal organization was reported for actin and tubulin filaments in both neurons and glial cells (Gascuel et al., 1991). The binding of phalloidin which we observed in growth cones of neurons suggests that actin filaments contribute to the extension of neurites.

The anti-HRP epitope, a powerful neuronal marker in studies of insect neuro-development (Jan \& Jan, 1982; Snow et al., 1987), is conserved at least in some membrane constituents of the regenerating processes of cultured honeybee neurons, although firm conclusions regarding the glycoprotein composition of the sprouting processes can not be drawn from our immunocytochemical results. The anti HRP-antiserum labelled spherical cells with well developed 
neurites more intense than cells with a flatter appearance containing translucent granules in the cytoplasm. A common feature of some types of insect glia is the deposit of materials like glycogen or lipids in storage bodies (Wigglesworth, 1960; Hoyle, 1986). Since during dissection any adhering tissue and the ganglion sheath was carefully removed from the ganglion, we propose that these flat multipolar cells are derived from the CNS and are of glial origin whereas the intensely stained cells are neurons.

\section{Neurotransmitter phenotype}

Neurotransmitter phenotype is a fundamental cellular property of neurons which directly relates to their function in the intact nervous system. Cultures of Periplaneta (Lees \& Beadle, 1988) and Drosophila (Wu et al., 1983; Wu, 1988) synthesize and accumulate neurotransmitters or their precursors. We have directly visualized neurotransmitters like GABA or glutamate in distinct neurons in vitro by means of immunocytochemistry. Since the frequency of the GABA-IR cells in vitro agrees closely with the expectation based on the known distribution of cells in vivo (Schäfer \& Bicker 1986), it is likely that the immunoreactive neurons have retained their transmitter phenotype in our culture system.

The motoneurons of the honeybee are glutamateIR, which is in agreement with the current view that the excitatory neuromuscular junction in arthropods is glutamatergic. In addition glutamate-IR was described in several groups of interneurons like the monopolar cells of the lamina or the large ocellar interneurons of the dorsal protocerebrum (Bicker et al., 1988). Glutamate immunoreactivity has been detected in cultures prepared from the optic lobes, the protocerebrum, and the suboesophageal ganglion. Thus we propose, that glutamate-IR suboesophegeal neurons in vitro represent motoneurons.

The mushroom body intrinsic Kenyon cells have been reported to contain taurine immunoreactivity of graded intensities (Schäfer et al., 1988; Bicker, 1991). The larger cell bodies at the rims of the calycal cups were stronger immunoreactive than the smaller more centrally located perikarya. We observed a similar correspondence of soma size and intensity of taurineIR in vitro.

Putative cholinergic pathways have been located in the brain of the honeybee by histochemical staining for $\mathrm{AChE}$ and the mapping of $\alpha$-Bgt binding sites (Kreissl \& Bicker, 1989; Scheidler et al., 1990), indicating for example nicotinic cholinergic transmission in the optic lobes and in a subset of antennoglomerular tract fibres. The expression of AChE activity and $\alpha$-Bgt binding in a low percentage of the cultured neurons suggests that our culture system may also preserve the neurochemical properties of a cholinergic phenotype.

The immunocytochemical demonstration of GABA, glutamate, and taurine, as well as the expression of the cholinergic markers $\mathrm{AChE}$ and $\alpha$-Bgt binding in the cultured neurons, suggest that our culture system preserve neurochemical phenotypes. Although definite conclusions as to whether individual neurons retain or change transmitter phenotype will only be possible when identified cells (e.g. retrogradely labelled motoneurons) have been placed in culture, our results indicate that the neurochemical properties of neurons provide convenient markers for the identification of individual cell types within the cultured subpopulations of neurons derived from different brain areas.

\section{Identification of living neurons}

The neuronal uptake of fluorescent latex beads after plating provided a convenient method to label all neurons belonging to a certain brain area. This method allowed us to distinguish between living neurons of co-cultured neuropiles without severe effects on outgrowth and viability.

The identification of neuronal cell types by morphological criteria appears to be of limited use, since normal cell shapes are drastically changed in our culture conditions. One of the most frequently employed labelling technique is the application of monoclonal antibodies recognizing specific surface antigens. We identified living relay neurons in dissociated cultures of the antennal lobes by immunofluorescence with a monoclonal antibody which stained the somata and processes of antennoglomerular tract neurons in situ and in vitro. Physiological properties and structural plasticity of the olfactory relay neurons linking antennal lobes and mushroom bodies can therefore be analyzed in isolation from the intact nervous system. In addition, since neurons originating from different brain areas form neuritic contacts in co-culture, our primary cell culture system. appears to be promising for an investigation of cellular mechanisms underlying proboscis extension learning in honeybees.

\section{Acknowledgements}

We wish to thank Alois Hofbauer for the gift of a monoclonal antibody. This work was supported by a grant of the Deutsche Forschungsgemeinschaft ( $B$ 262/3-2). 


\section{References}

BEADLE, C. A., BERMudez, I. \& BEADLE, D. J. (1987) Amino acid uptake by neurones and glial cells from embryonic cockroach brain growing in vitro. Joumal of Insect Physiology 33, 761-8.

BEADLE, D. J. \& HICKS, D. (1985) Insect nerve cell culture, In Comprehensive Insect Biochemistry, Physiology, and Pharmacology Vol. 5 (edited by KERKUT, G. \& GILBERT, L.) pp. 181-211. Oxford: Pergamon Press.

BICKER, G. (1991) Taurine-like immunoreactivity in photoreceptor cells and mushroom bodies: a comparison of the chemical architecture of insect nervous systems. Brain Research 560, 201-6.

BICKER, G. \& MENZEL, R. (1989) Chemical codes for the control of behaviour in arthropods. Nature 337, 33-9.

BICKER，G., SCHÄFER, S. \& REHDER, v. (1987) Chemical neuroanatomy of the honeybee brain. In Neurobiology and Behavior of Honeybees (edited by MENZEL, R. \& MERCER, A) pp. 202-24. Berlin, Heidelberg, New York: Springer Verlag.

BICKER, G:, SCHÄFER, S., OTTERSEN, O. P. \& STORMMATHISEN, J. (1988) Glutamate-like immunoreactivity in identified neuronal populations of insect nervous systems. Journal of Neuroscience 8, 2108-22.

BRAUN, G. \& BICKER, G. (1992) Habituation of an appetitive reflex in the honeybee. Journal of Neurophysiology 67, 588-98.

CHEN, J, S. \& LEVI-MONTALCINI, R. (1970) Axonal growth from insect neurons in glia-free cultures. Proceedings of the National Academy of Sciences (USA) 66, 32-9.

FRISCH, K. V. (1967) The Dance Language and Orientation of Bees. Cambridge: Harvard University Press.

GAScuel, J., MASSON, C. \& BEADLE, D. J. (1991) The morphology and ultrastructure of antennal lobe cells from pupal honeybees (Apis mellifera) growing in culture. Tissue and Cell 23, 547-59.

GILES, D. P. \& USHERWOOD, P. N. R. (1985) Locust nymphal neurones in culture: a new technique for studying the physiology and pharmacology of insect central neurones. Comparative Biochemistry and Physiology 80C, 53-9.

HAYASHI, J. H. \& HILDEBRAND, J. G. (1990) Insect olfactory neurons in vitro. Morphological and physiological characterization of cells from the developing antennal lobes of Manduca sexta. Journal of Neuroscience 10, 848-59.

HOfBAUER, A. (1987) Monoclonal antibodies reveal anatomical details in the Drosophila brain. In New Frontiers in Brain Research (edited by ELSNER, N. \& CREUTZFELDT, O.) p. 253. Stuttgart, New York: G. Thieme Verlag.

HOYLE, G. (1986) Glial cells of an insect ganglion. Journal of Comparative Neurology 246, 85-103.

JAN, L. Y. \& JAN, Y. N. (1982) Antibodies to horseradish peroxidase as specific neuronal markers in Drosophila and in grasshopper embryos. Proceedings of the National Academy of Sciences (USA) 79, 2700-4.

KAATZ, H-H., HAGEDORN, H. H. \& ENGELS, W. (1985) Culture of Honeybee organs: development of a new medium and the importance of tracheation. In Vitro Cellular and Developmental Biology 21, 347-52.

KARNOVSKY, M. \& ROOTS, J. L. (1964) A direct coloring method for cholinesterases. Journal of Histochemistry and Cytochemistry 12, 219-22.
KREISSL, S. \& BICKER, G. (1989) Histochemistry of acetylcholinesterase and immunocytochemistry of an acetylcholine receptor-like antigen in the brain of the honeybee. Journal of Comparative Neurology 286, 71-84.

KREISSL, S. \& BICKER, G. (1990) The brain of the honeybee in cell culture. In Brain-Perception-Cognition, Proceedings of the 18th Göttingen Neurobiology Conference (edited by ELSNER, N. \& BARTH, F. G. ) p. 458. Stuttgart: Thieme.

LEES, G. \& BEADLE, G. (1988) Cockroach neuronal cultures as models for investigating the neuropharmacology of the insect nervous system. In Cell Culture Approaches to Invertebrate Neuroscience (edited by BEADL E, D. J., LEES, G. \& KATER, S. B.) pp. 109-47. London, San Diego: Academic Press.

MARSHALL, J., BUCKINGHAM, S. D., SHINGAI, R., LUNT, G. G., GOOSEY, M. W., DARLISON, M. G., SATTELLE, D. B. \& BARNARD, E. A. (1990) Sequence and functional expression of a single $\alpha$ subunit of an insect nicotinic acetylcholine receptor. EMBO Journal 9, 4391-8.

MAUELSHAGEN, J., HAMMER, M. \& BRAUN, G. (1989) Neural correlates of sensitization in honeybees. In Neural Mechanisms of Behavior - Proceedings of the 2 nd International Congress of Neuroethology (edited by ERBER, J., MENZEL, R., PFLÜGER, H. J. \& TODT, D.) p. 220. Stuttgart, New York: Georg Thieme Verlag.

MENZEL, R. \& MERCER, A., eds (1987) Neurobiology and Behavior of Honeybees Berlin, Heidelberg, New York: Springer Verlag.

MENZEL, R., ERBER, J. \& MASUHR, T. (1974) Learning and memory in the honeybee. In Experimental Analysis of Insect Behaviour (edited by BARTON-BROWNE, L) pp. 195-217. Berlin: Springer.

MERCER, A. R. \& MENZEL, R. (1982) The effects of biogenic amines on conditioned and unconditioned responses to olfactory stimuli in the honeybee, Apis mellifera. Journal of Comparative Physiology 145, 363-8.

MOBBS, P. G., (1982) The brain of the honeybee Apis mellifera. I. The connections and spatial organization of the mushroom bodies. Philosophical Transactions of The Royal Society of London B 298, 309-54.

MOBBS, P. G. (1985) Brain structure. In Comprehensive Insect Physiology Biochemistry and Pharmacology, Vol. 5 (edited by KERKUT, G. A. \& GILBERT, L. I.) pp. 299-370. Oxford: Pergamon Press.

REHDER, V., BICKER, G. \& HAMMER, M. (1987) Serotoninimmunoreactive neurons in the antennal lobes and suboesophageal ganglion of the honeybee. Cell and Tissue Research 247, 59-66.

SCHÄFER, S. \& BICKER, G. (1986) Distribution of GABA-like immunoreactivity in the brain of the honeybee. Journal of Comparative Neurology 246, 287-300.

SCHÄFER, S., BICKER, G., OTTERSEN, O. P. \& STORMMATHISEN, J. (1988) Taurine-like immunoreactivity in the brain of the honeybee. Journal of Comparative Neurology. $268,60-70$.

SCHEIDLER, A. K., KAULEN, P., BRÜNING, G. \& ERBER, J. (1990) Quantitative autoradiographic localization of $\left[{ }^{125} \mathrm{I}\right] \alpha$-bungarotoxin binding sites in the honeybee brain. Brain Research 534, 332-5.

SNOW, P. M. , PATEL, N. H., HARRELSON, A. L, \& GOODMAN, 
C. S. (1987) Neural-specific carbohydrate moiety shared by many surface glycoproteins in Drosophila and grasshopper embryos. Journal of Neuroscience 7, 4132-44.

STENGL, M. \& HILDEBRAND, J. G. (1990) Insect olfactory neurons in vitro: morphological and immunocytochemical characterization of male-specific antennal receptor cells from developing antennae of male Manduca sexta. Journal of Neuroscience 10, 837-47.

Štrausfeld, N. J. (1976) Atlas of an Insect Brain. Berlin, Heidelberg, New York: Springer Verlag.

WIGGLESWORTH, V. B. (1960) The nutrition of the central nervous system in the cockroach Periplaneta americana $\mathrm{L}$. Journal of Experimental Biology 37, 500-12.

WU, C.-F. (1988) Neurogenetic studies of Drosophila central nervous system neurons in culture. In Cell Culture Approaches to Invertebrate Neuroscience (edited by BEADLE, D. J., LEES, G. \& KATER, S. B.) pp. 149-88. London, San Diego: Academic Press.

WU, C.-F., SUZUKI, N. \& POO, M-M. (1983) Dissociated neurons from normal and mutant Drosophila larval central nervous system in cell culture. Journal of Neuroscience 3, 1888-99. 